ISSUES IN MEDICINE

\title{
Establishing a Health Promotion and Development Foundation in South Africa
}

A M Perez, O A Ayo-Yusuf, K Hofman, S Kalideen, A Maker, D Mokonoto, N Morojele, P Naidoo, C Parry, K Rendall-Mkosi, Y Saloojee

\begin{abstract}
A M Perez is Deputy Dean of the Faculty of Health Sciences at the University of Cape Town. O A Ayo-Yusuf is an Associate Professor at the Department of Community Dentistry and the School of Health Systems \& Public Health, Faculty of Health Sciences, at the University of Pretoria. $K$ Rendall-Mkosi is a senior lecturer at the School of Health Systems and Public Health, Faculty of Health Sciences, University of Pretoria. K Hofman is Associate Professor in the MRC/Wits Rural Public Health and Health Transitions Research Unit, School of Public Health, University of the Witwatersrand, Johannesburg. S Kalideen is Advocacy Manager of Soul City:Institute for Health and Development Communication in Johannesburg. A Maker is a researcher at the Sonke Gender Justice Network, Johannesburg. M D Mokonoto is a Senior Lecturer at the School of Public Health, University of the Witwatersrand, Johannesburg. N Morojele is a Chief Specialist Scientist and the Deputy Director of the Alcohol \& Drug Abuse Research Unit, Medical Research Council, Pretoria, and School of Public Health, University of the Witwatersrand. P Naidoo is Research Director in the Population Health, Health Systems and Innovations Programme at the Human Sciences Research Council and Extraordinary Professor at the University of the Western Cape. C Parry is Director of the Alcohol \& Drug Abuse Research Unit at the Medical Research Council $(M R C)$ and an Extraordinary Professor in the Department of Psychiatry at Stellenbosch University. Y Saloojee is Executive Director of the National Council Against Smoking, Johannesburg.
\end{abstract}

Corresponding author: G Perez (gonda.perez@uct.ac.za)

South Africa has a 'quadruple burden of disease'. One way to reduce this burden, and address the social determinants of health and social inequity, could be through health promotion interventions driven by an independent Health Promotion and Development Foundation (HPDF). This could provide a framework to integrate health promotion and social development into all government and civil society programmes. On priority issues, the HPDF would mobilise resources, allocate funding, develop capacity, and monitor and evaluate health promotion and development work. Emphasis would be on reducing the effects of poverty, inequity and unequal development on disease rates and wellbeing. The HPDF could also decrease the burden on the proposed National Health Insurance (NHI) system. We reflect on such foundations in other countries, and propose a structure for South Africa's HPDF and a dedicated funding stream to support its activities. In particular, an additional $2 \%$ levy on alcohol and tobacco products is proposed to be utilised to fund the HPDF.

S Afr Med J 2013;103(3):147-149. DOI:10.7916/SAMJ.6281

South Africa (SA) is a middle-income country with a low life expectancy of 55.3 years for males and 60.4 years for females. ${ }^{[1]}$ Contributing to this is the 'quadruple burden of disease': infectious diseases related to poverty and underdevelopment; a growing burden of non-communicable and chronic diseases; rising rates of injury; and the HIV/AIDS pandemic. ${ }^{[2]}$ SA spends approximately $8.6 \%$ of its gross domestic product (GDP) on health. ${ }^{[3]}$ However, expected health outcomes are not being achieved as the expenditure is essentially focused on the sick (as demonstrated by hospital expenditure increasing by $15.4 \%$ over the last 3 years) ${ }^{[3]}$ This pattern must change if we are to improve the health of the nation.

The systematic impoverishment of black people over 350 years was characterised by low wages, poor education, limited or no access to water and sanitation, poor housing and lack of access to transport. These remain the drivers of the health inequities in SA. ${ }^{[4]}$ While national social grants for children, the disabled and the elderly provide some relief from poverty and unemployment, the effect is insufficient to improve public health. ${ }^{[4]}$ Establishing a National Health Insurance (NHI) scheme in SA has the potential to improve healthcare delivery, but is insufficient to address the determinants shown to have the greatest effect on health in other parts of the world.

In SA, the Gini co-efficient of inequality increased from 0.640 in 1995 to 0.679 in $2008,{ }^{[5]}$ signifying an increase in inequality and identifying SA as one of the most unequal societies in the world. With a high burden of poverty-related disease, all social sectors need to be involved in addressing the abysmal trends in health indicators. Efforts are underway to improve service quality and to revitalise primary healthcare (PHC) in SA..$^{[6,7]}$ This should increase the numbers of patients utilising the services, many of whom suffer from preventable diseases. However, without tremendous efforts to promote health and prevent disease, attempts to revitalise PHC will have little chance of success.

\section{Why a Health Promotion and Development Foundation for SA?}

Globally, health promotion has emerged as a viable tool for comprehensive and equitable health and social development. ${ }^{[8]}$ Recognising the importance of sustained activities that promote public and individual health, as well as the need for continuous community engagement, various countries have established health promotion foundations (HPFs). ${ }^{[10]}$

HPFs generally operate independently of government, but support government priorities and contribute to the development of evidencebased public policy ${ }^{[10]}$ An HPF can also provide a research platform for policy development, advocacy, intersectoral planning and policy implementation. ${ }^{[13,1,4]}$ In the medium to long term, an HPF reduces the costs associated with curative care, while promoting broader social and development goals. ${ }^{[10]}$

The first HPF, VicHealth, was established in 1987 in Victoria, Australia, after the Victorian Tobacco Act of 1987 allowed the 
state government to collect taxes on tobacco products to fund VicHealth. One of the HPF's first strategies was to buy out the sports sponsorships of tobacco companies. It could also fund other activities such as the Anti-Cancer Council established by Victoria's Sunsmart Campaign. ${ }^{[1]]}$ ThaiHealth, Thailand's successful HPF formed under the Health Promotion Foundation Act of 2001, is a semi-independent state agency funded by a $2 \%$ surcharge tax on tobacco and alcohol products. Its annual expenditure includes an average of US $\$ 4.7$ million on campaigns to address road traffic accidents, consequently reducing traffic accidents by $31 \%$ and road injury deaths by $10 \%$ between 2004 and 2009. ${ }^{[10]}$ Currently, about 16 states or countries have HPFs funded by dedicated tobacco and/or alcohol levies, or from general government revenues, including Austria, Estonia, Qatar, Mongolia, New Zealand, Korea, Switzerland, Tonga and the American state of Arizona.

Taking these successes into account, alongside SA's progress towards an $\mathrm{NHI}$ and pending legislation to ban alcohol advertising, in November 2011 the National Council Against Smoking together with Soul City organised a workshop to explore the feasibility of establishing an HPF in SA, to be called the Health Promotion and Development Foundation (HPDF). A task team of volunteers and organisations has since formed the Health Promotion and Development Network (HPDNet), which presented a document, 'Motivation for the establishment of a health promotion and development foundation for South Africa ${ }^{\text {?[12] }}$ to the Minister of Health and the Inter-Ministerial Committee (IMC) on Substance Abuse.

\section{Purpose and aim}

The purpose of the proposed HPDF is to provide a framework for SA to integrate health promotion and social development into all government and civil society programmes, and to enable individuals to increase control over, and improve, their health and wellbeing. The primary aim of the HPDF would be to mobilise resources, allocate funding, develop capacity, and monitor and evaluate health promotion and development work on priority issues in SA. The emphasis would be on reducing the effects of poverty, inequity and unequal development on health and wellbeing, and on addressing factors such as commercial marketing practices that promote ill health.

\section{Strategies}

The HPDF, together with partners, would undertake to: (i) support strategic thinking and advocacy on health promotion and social development issues; (ii) support special projects to further the health promotion and development agenda, including projects commissioned by the foundation and those where funding is sought by external applicants; (iii) conduct research and support knowledge dissemination through grants, evaluation research and knowledge translation; (iv) support sporting and cultural organisations that directly or indirectly promote health and social capital; and $(v)$ support capacity building in health-promoting activities.

\section{Governance}

International best practice shows that effective HPFs need to be able to make autonomous decisions about policies, programmes and funding. However, while acting independently from government, their policies should remain within government parameters. ${ }^{[15]}$ As well as bypassing bureaucratic deficiencies, the autonomy of HPFs provides greater freedom to advocate for a wider range of health and development interventions. Government oversight could be exercised through active involvement in the HPF's board. For example, in Thailand, the Prime Minister chairs the governing board and the
Minister of Health is the vice-chair. ${ }^{[16]}$ At VicHealth, all political parties are represented on the board.

\section{Partners and stakeholders}

Government should be a major partner in an HPDF - at all levels (local, provincial and national). The departments involved should include health, social development, transport and traffic, development planning, human settlements, and education. Other key stakeholders and partners should include civil society (including community representatives), universities and research organisations such as the Medical Research Council (MRC) and Human Sciences Research Council (HSRC), and the private sector.

\section{Financing}

An HPDF requires a long-term and sustainable revenue base to support its activities and to ensure long-term and proactive planning. Internationally, HPF sources of funding have included a surcharge on alcohol and tobacco products, a levy on social health insurance or value added tax, or the government's general budget (Table 1). ${ }^{[17]}$ Botswana uses funds from an alcohol levy (currently $40 \%$ of the retail price) to fund activities such as educational programmes, promoting alcohol-free youth programmes, counter advertisements, monitoring and research. Scotland has passed legislation providing for local councils to apply for a social responsibility levy on alcohol retailers. ${ }^{[17]}$

Imposing a surcharge on tobacco and alcohol industries, and directing the funds to the HPDF, is a preferred option in SA for 3 reasons:

- A surcharge benefits public health by directly changing behaviour: increased prices discourage consumption and stimulate good behaviour (e.g. quitting smoking and drinking less).

- It shifts the burden of paying for actions to reduce the social, economic and health costs of tobacco and alcohol use from the government to the industries - the basis of the 'polluter pays' principle.

- It can generate significant long-term, sustainable revenue.

A surcharge would require the tobacco and alcohol industries to pay an additional percentage of their total revenues (in addition to excise taxes) to the Treasury, which would be credited to the HPDF account. The surcharge would not affect Treasury's ability to set and collect excise taxes. While the National Treasury has indicated that it is not in favour of earmarked taxes, ${ }^{[18]}$ many such dedicated taxes are already in place, including: the Road Accident Fund (surcharge on fuel purchases), carbon emission taxes on vehicles; toll roads; car license fees; the Responsible Gambling Programme (levy on gambling revenue); and the levy on plastic bags..$^{[19]}$

A surcharge has the added benefit of increasing the cost of products that are harmful to health, as companies invariably pass these costs on to the consumer. Research has shown that raising the price of harmful products decreases their consumption and prevents young people from starting to use them. In SA between 1993 and 2000 , per capita cigarette consumption decreased by a massive $37 \%$ in response to a $92 \%$ increase in real price. ${ }^{[2]}$

\section{Conclusion}

There is overwhelming evidence of the health and economic benefits of allocating resources to promoting health and development, reducing illness by improving living environments, and promoting healthy lifestyles. ${ }^{[20]}$ HPFs have been established in various parts of the world to intensify and enable environments for health promotion efforts. The ultimate result is immense savings in disease treatment. ${ }^{[17]}$ 


\section{FORUM}

Table 1. Sources and levels of funding for selected HPFs ${ }^{[16]}$

\begin{tabular}{lcccl}
\hline HPF & Population (million) & Annual budget (US\$) & Annual budget per person (US\$) & Source of funding \\
\hline ThaiHealth & & & & $2 \%$ surcharge on \\
Australian HPF & 61 & 100 & 2.00 & tobacco and alcohol \\
VicHealth & 8 & 9 & 1.09 & Value added tax \\
Healthway & 5 & 27 & 4.60 & Treasury budget \\
(Western Australia) & 1.8 & 20 & 9.09 & Treasury budget \\
Korean HPF & 45 & 19 & 0.42 & Tobacco excise tax \\
Malaysian HPF & 20 & 7 & 0.26 & Treasury budgets \\
Swiss HPF & 7.5 & 16.7 & 2.20 & Health insurance \\
HPF = health promotion foundation. & & & &
\end{tabular}

Health promotion and development is a comprehensive and inclusive social and political process. HPFs work collaboratively across all levels of society, encouraging intersectoral co-operation.

An HPDF would: (i) bring together all government, civil society and private sector stakeholders and experts in health promotion and social development; (ii) complement and enhance government health promotion initiatives by working in parallel with government departments in their key focus areas; (iii) potentially provide a sustainable mechanism for financing, implementing and co-ordinating health promotion initiatives, thereby acting as an additional health financing option for government's public health mandate within the NHI; and (iv) strengthen the NHI but, importantly, not compete for funds that have been earmarked for treatment. Other strengths of HPFs include low administrative costs, lack of bureaucratic impediments, quick turnaround and response time, inclusion of community inputs, and the potential to shield governments from unpopular funding decisions. HPDFNet is therefore urgently mobilising support for the establishment of an HPDF in SA.

1. Statistics South Africa. Millenium Development Goals Country Report. Pretoria: SSA, 2010. 2. Bradshaw D, Groenewald P, Laubscher K, et al. Initial burden of disease estimates for South Africa, 2000. S Afr Med J 2003;93(9):682-688.

Blecher M, Kollipara A, Dejager P, Zulu N. Health Financing. In: Padarith A, English R, eds. The South African Health Review 2011. Durban: Health Systems Trust, 2011. http://www.hst.org.za/pblications/ south-africa-health-review-2011
4. Coovadia H, Jewkes R, Barron P, Sanders D, McIntyre D. The health and health system of South Africa: Historical roots of current public health challenges. Lancet 2009;374:817-834. [http://dx.doi. (10.1016/S0140-6736(09)60951-X]

5. Office of the Presidency. Development Indicators. Pretoria: Office of the Presidency, 2009. http://www. thepresidency.gov.za/learning/me/indicators/2009/indicators.pdf (accessed 16 August 2012).

thepresidency.gov.za/learning/me/indicators/2009/indicators.pdf (accessed 16 A

6. National Department of Health. Strategic Plan. Pretoria: DoH, 2008/09-2010/11. National Department of Health. Discussion Document: Re-engineering Primary Health Care in South
Africa. Pretoria: DoH, 2010 .

All A. Social capital and health promotion: A review. Soc Sci and Med 2000;51(6):871-885. National Treasury. Budget Review 2012. Pretoria: National Treasury, 2012. http://www.treasury.gov.

10. Vathesatogkit P, Lian TY, Ritthiphakdee B. Lessons Learnt in Establishing a Health Promotion Fund. Bangkok: Southeast Asia Tobacco Control Alliance (SEATCA), 2011. http://seatca.org/dmdocuments lessons\%20Learned\%20in\%20establishing\%20HP\%20fund.pdf (accessed 16 June 2012).

11. Victoria Health Promotion Foundation. The Story of VicHealth: A World First in Health Promotion Melbourne: Victoria Health Promotion Foundation, 2005.

12. Health Promotion and Development Network. Motivation for the establishment of a health promotion and development foundation for South Africa. Johannesburg: HPDNet, 2012

13. Oddy WH, Holman CDJ, Corti B, Donovan RJ. Epidemiological measures of participation in community health promotion projects. Int J Epidemiol 1995;24:1013-102

14. Holman CDJ, Donovan RJ, Corti B, Jalleh G. Evaluating projects funded by the Western Australian Health Promotion Foundation: First results. Health Promot Int 1996;11:75-88.

15. Vathesatogkit P. Using Innovation in Tobacco/Alcohol Taxation in Promoting Health. Soul City and National Council Against Smoking Health Promotion Indaba 2011, Johannesburg.

16. ThaiHealth website. http://enthaihealth.or.th/about (accessed 12 June 2012).

17. International Network of Health Promotion Foundations website. http://www.hp-foundations.net (accessed 24 April 2012)

18. Parry C. Making the Polluter Pay: The case for a Health Promotion Foundation in SA funded by a Levy on Alcohol. Soul City and National Council Against Smoking Health Promotion Indaba 2011,

Johannesburg.
19. Parry CDH, Myers B, Thiede M. The case for an increased excise tax on alcohol in South Africa. S Afr J Econ 2003; $71: 265-281$.

20. Harris A, Mortimer D. Funding illness prevention and health promotion in Australia: A way forward. Australia and New Zealand Health Policy 2009;6:25. [http://dx.doi.org/10.1186/1743-8462-6-25.

21. Van Walbeek CP. A simulation model to predict the fiscal and public health impact of change in cigarette excise taxes. Tob Control 2010;19:31-36. [http://dx.doi.org/10.1136/tc.2008.028779]

Accepted 17 September 2012 